\title{
How do Saudi Children and Their Mothers Evaluate Religion-Based Exclusion?
}

\author{
Munirah Alsimah $^{1} \cdot$ Harriet R. Tenenbaum ${ }^{2} \cdot$ Patrice Rusconi $^{2}$
}

Accepted: 30 January 2021 / Published online: 25 February 2021

(c) The Author(s) 2021

\begin{abstract}
This study focuses on Saudi mothers' and their children's judgments and reasoning about exclusion based on religion. Sixty Saudi children and their mothers residing in Saudi Arabia and 58 Saudi children and their mothers residing in the United Kingdom were interviewed. They were read vignettes depicting episodes of exclusion based on the targets' religion ordered by peers or a father. Participants were asked to judge the acceptability of exclusion and justify their judgments. Both groups rated the religious-based exclusion of children from peer interactions as unacceptable. Saudi children and mothers residing in the UK were less accepting of exclusion than were children and mothers residing in Saudi Arabia. In addition, children and mothers residing in the UK were more likely to evaluate exclusion as a moral issue and less likely as a social conventional issue than were children and mothers residing in Saudi Arabia. Mothers in the UK were also less likely to invoke psychological reasons than were mothers in Saudi Arabia. Children's judgments about exclusion were predicted by mothers' judgments about exclusion. In addition, the number of times children used moral or social conventional reasons across the vignettes was positively correlated with mothers' use of these categories. The findings, which support the Social Reasoning Development model, are discussed in relation to how mothers and immersion in socio-cultural contexts are related to children's judgments and reasoning about social exclusion.
\end{abstract}

Keywords Social reasoning $\cdot$ Peer exclusion $\cdot$ Parent-child socialization $\cdot$ Social context

\section{Highlights}

- Saudi mothers and children in the UK and Saudi Arabia rated religion-based exclusion as wrong.

- Families living in the UK were less accepting of religion-based exclusion than those living in Saudi Arabia.

- Mothers with higher levels of education were less accepting of religion-based exclusion.

- Children's judgments reflected mothers' judgments about social exclusion.

- Children's moral and social conventional reasoning was related to mothers' explanations.

Children are often excluded from peer groups based on social groups, such as ethnicity and religion. Exclusion has a negative effect on children with many who are rejected by peers reporting loneliness, depression, internalizing problems, low academic performance, and lower cognitive functioning (Buhs \& Ladd, 2001; Buhs et al., 2006; Ladd et al., 2008; Pedersen et al., 2007; Prinstein \& Aikins, 2004;

Harriet R. Tenenbaum

h.tenenbaum@surrey.ac.uk

King Saud University, Riyadh, Saudi Arabia

2 University of Surrey, Guildford, England
Tobia et al., 2017). As a result of the negative effects of peer exclusion, this topic has received considerable attention from researchers (for a review, see Killen \& Rutland, 2011). The current study extends this literature through the examination of differences in judgments and reasoning about exclusion based on religion in Saudi children and their mothers residing in Saudi Arabia and the UK.

\section{Theoretical Background}

The Social Reasoning Development model (SRD, Killen et al., 2017; Killen et al., 2015; Rutland \& Killen, 2017) informed this study. SRD theory proposes that individuals 
use different types of reasonings to evaluate social events and making decision in intergroup contexts. Additionally, SRD focuses on age-related changes in how individuals evaluate issues in intergroup contexts. This theory draws from developmental social identity theory (Abrams \& Rutland, 2008), which examines how children develop their social identities to become a member of a social group. Chidren's identification with a social group influences their understanding and behaviors in intergroup interactions. Further, SRD draws on social domain theory (SDT, Smetana, 2013; Smetana et al., 2014; Turiel, 1998), which examines how children negotiate their understanding of social issues by recruiting different forms of reasoning.

From this perspective, understanding how individuals evaluate intergroup exclusion is grounded in understanding group identity, contextual features of the exclusion situation, and the forms of reasoning that are recruited to make sense of the situation. In terms of reasoning, SDT finds that young people draw on moral (e.g., issues of fairness and rights), social conventional (e.g., group functioning), and psychological (e.g., personal choice) reasoning to understand situations. Individuals tend to use moral reasoning to condemn exclusion and social conventional and personal choice reasoning to condone exclusion (Killen \& Rutland, 2011; Killen et al., 2002).

Previous research has looked at the influence of parents' norms on social exclusion. Brenick and Romano (2016) examined adolescents' perceptions of parents' outgroup norms. When Jewish-American adolescents perceived that their parents held positive attitudes towards Arab Americans, the adolescents were likely to evaluate exclusion as unacceptable. In contrast, when adolescents perceived that their parents held negative attitudes towards Arab Americans, the adolescents were more likely to include ingroup members than outgroup members. This study provides evidence that children's judgments of the acceptability of exclusion might be influenced by parents' norms. However, Brenick and Romano did not directly measure parents' attitudes. Therefore, we do not know whether it is adolescents' perceptions of parents' norms or parents' norms themselves that influence children's beliefs about exclusion.

Evidence that mothers' and children's views about exclusion might be related comes from a meta-analysis of 131 studies with over 45,000 parent-child dyads with children between 4 to 18 years. In their meta-analysis, Degner and Dalege (2013) found a positive relation with a medium effect size between parents and children in their intergroup attitudes across all age groups. However, their meta-analysis focused on attitudes toward outgroups rather than exclusion. In addition, their meta-analysis relied on samples in which over $93 \%$ of participants came from Western countries.

\section{Middle Eastern Samples}

Unfortunately, the lack of research on Middle Eastern samples in developmental psychology hinders our understanding of differences based on cultural community (Nielsen et al., 2017). This lack of attention to diversity may skew findings to suggest that parents' role is moderate. Indeed, in many Middle Eastern countries, the authority of adults (and in particular, parents) and the family play a significant role in children's lives (Almalki, 2020; AlSimadi \& Atoum, 2000; Tamis-LeMonda et al., 2008). Studies conducted with the Israeli Druze found that children had a high level of respect for the authority of adults (Turiel \& Wainryb, 2000; Wainryb \& Turiel, 1994). The influence of parents' authority extends to include children's attitudes towards in-group and out-group members. Bar-Tal (1996) found parents to be the main source for Israeli children's information, stereotypes, social categorization, and attitudes towards Arabs. Saudi Arabian young adults report that they conform to their parents' decisions and accommodate their parents more than do Chinese or American young adults (Guan \& Li, 2017). These previous studies have highlighted the authority of parents and family on children's attitudes and the importance of obedience to parents in the Middle East. However, no research has yet examined the parentchildren relationship in the judgment of peer exclusion, a gap that the current study aimed to fill.

\section{Cultural Communities}

One previous study examined judgments and reasoning about exclusion in children (but not their mothers) from Middle Eastern countries. Brenick and colleagues (2010) investigated cultural stereotyping and evaluation of peer exclusion based on language and country among Palestinian, Jordanian, Israeli-Palestinian, and Israeli-Jewish children. Children living in areas with more negative tensions between groups (Jordanian and Palestinian children) had more negative views of the outgroup (either Jewish or Arab children) than children living in less conflictual sites (Israeli-Jewish and Israeli-Palestinian children). Thus, the cultural context in which children reside play a role in their judgments and reasoning. However, how the same Middle Eastern social group is influenced by a different, non-Middle Eastern cultural context is yet to be investigated.

\section{The Different Cultural Contexts in Saudi Arabia and UK}

There are many ways in which Saudi Arabia and the UK differ that make them ideal to study cultural modifications in beliefs. We focus on two of these ways relevant to the 
current study: Religious practice and intergroup contact. Similar to other Middle Eastern countries, citizens in Saudi Arabia have a strong religious identity with about 80-95\% of citizens identifying as Sunni Muslims (Almalki, 2020; Matthiesen, 2015; Metz, 1993). As a result, Saudi Arabia is a homogenous society with respect to religion (Al-Rasheed, 2013). The official religion in Saudi Arabia is Sunni Islam with Saudi Arabia's practices, laws, and educational curriculum built on Sunni Islam. Islam has a strong influence on Saudi citizens as a national and social identity (Nevo, 1998). Religious conversion (i.e., leaving Islam or converting from Islam to a different religion) is forbidden, and all citizens must be Muslims. Additionally, Saudi children have a strong sense of religious-based identity. All mothers in this sample were practicing Muslims who observed all religious traditions (e.g., fasting during Ramadan, dressing modestly, avoiding alcohol and pork products).

In contrast, despite having a state religion (the Church of England), there is freedom of religion in the UK and more than half the population in the UK declares themselves as having no religion (Phillips et al., 2018). In addition, the Equalities Act of 2010 outlawed discrimination based on religion including "a lack of belief". Given the centrality of religion, although in opposite ways, in both Saudi Arabia and the UK, the current study focuses on religion-based forms of exclusion rather than on exclusion in general or other types of exclusion.

A second way in which the UK and Saudi Arabia differ is in the degree of intergroup contact afforded to individuals with respect to religion. Given the level of religious homogeneity in Saudi Arabia (Al-Rsheed, 2013), there is little opportunity for intergroup contact with outgroup members (non-Muslims) compared to the UK. Intergroup contact theory suggests that positive contact between an individual and individuals from another group reduces prejudice against outgroup members (Allport, 1954; Killen \& Rutland, 2011; Pettigrew \& Tropp, 2008). Further, contact with outgroup members can promote moral reasoning such as the notion that is is unfair to exclude outgroup members and motivate children to challenge negative stereotypes about outgroups based on their own contact with outgroup members (Killen \& Rutland, 2011). Intergroup contact between groups moderates judgments of peer exclusion in children. Children with high levels of contact were less accepting of exclusion of outgroup members than those with lower levels of contact (Crystal et al., 2008). Following from this idea, the level of intergroup contact in Jewish-American and non-Arab/non-Jewish American adolescents predicted the levels of acceptance of peer exclusion (Brenick \& Killen, 2014). Similarly, Brenick et al. (2019) found that an intervention based on intergroup contact was effective in encouraging Palestinian-Israeli and
Jewish-Israeli youth to evaluate exclusion of out-group members as wrong.

All the Saudi children in the UK in the present study attended state schools with large numbers of British majority children. All Saudi children in Saudi Arabia attended schools with only Muslim pupils. We would expect Saudi children residing in the UK, thus, to have less acceptance of peer exclusion and, in particular, when the outgroup is excluded.

\section{Education}

One concern with simply looking at those residing abroad as a monolithic group is that differences, such as parents' educational achievement, influences outcomes (Mistry et al., 2016). In relation to exclusion, education decreases people's levels of prejudice (Vogt, 1997). For this reason, we controlled for maternal educational level in all analyses and expected greater levels of education to be related to less support for exclusion, higher levels of moral reasoning, and lower levels of social conventional reasoning in mothers.

\section{Ingroup versus Outgroup Exclusion}

Another contextual factor of the exclusion situation we investigated was the group that was excluded. The literature on adults' exclusion of ingroup and outgroup members has shown that majority, ingroup members can express exclusionary attitudes towards outgroups (Gorodzeisky, 2013). However, the literature on the hurtful effects of the exclusion by ingroup and outgroup members is mixed. Some studies have shown that exclusion by an ingroup member is felt more strongly by the target (Bernstein et al., 2010; Sacco et al., 2014), whereas other studies have provided some evidence for the opposite effect (Goodwin et al., 2010; Williams et al., 2002), and other research has not shown any ingroup-outgroup difference in the hurtful feelings elicited in the target (Fayant et al., 2014; Gonsalkorale \& Williams, 2007; Smith \& Williams, 2004).

SRD's incorporation of Social Identity Theory (SIT) by Tajfel (1970) suggests that belonging to a group engenders a sense of pride, identity, and self-esteem. When an individual identifies her/himself with a certain group, the identity of this group will be the main component in her/his self-concept. Based on SIT (Turner \& Reynolds, 2001), categorizing individuals into groups is enough to produce ingroup bias, which stems from the motivation to boost one's own group self-esteem (Tajfel \& Turner, 1985). Of course, ingroup favouritism may not reflect hostility against outgroups (Nesdale, 2004). Children may exclude outgroup members if they believe this kind of behavior is considered appropriate by ingroup members (Killen \& Rutland, 2011). 
From this theoretical perspective, people should rate exclusion of ingroup members as less acceptable than exclusion of outgroup members.

\section{Age}

Given that age influences the strength of the relation between children's and parents' ratings, it is a dimension worthy of investigation. Intergroup attitude correspondence between parents and children was larger in older than younger age groups (Degner \& Dalege, 2013). Similarly, a meta-analysis (Tenenbaum \& Leaper, 2002) on gender attitudes found larger convergence in attitudes between children and parents in older than younger children. Thus, we would expect older children to have more similar attitudes to their mothers than younger children.

In addition, the SRD theory (e.g., Killen et al., 2017; Rutland \& Killen, 2017) suggests that the ability of children to weigh up multiple perspectives in their reasoning increases from childhood to adolescence. Children become more able to evaluate complex contexts with age (Killen et al., 2002). Adolescents begin to weigh up considerations of group functioning and ingroup loyalty (Killen \& Rutland, 2011) and have a greater understanding of group norms than younger children (Abrams et al., 2009). Younger children instead rely on stereotyped knowledge of outgroups more than do older children (Killen \& Rutland, 2011). From the SDT (e.g., Smetana, 2013; Smetana et al., 2014; Turiel, 1998), stereotyped reasoning is considered a social conventional type of reasoning. Although younger and older children use different types of social conventional reasoning, we would not expect differences in the total amount of social conventional reasoning. However, given a decrease in ingroup bias in older children compared with younger children (Abrams et al., 2009), we would expect less acceptance of peer exclusion in older than younger children. Thus, we investigated children aged 8, 10, and 12 years of age to look at the transition into adolescence.

\section{Hypotheses}

In sum, we proposed five sets of related hypotheses based on the literature reviewed. First, we expected that Saudi children and mothers residing in the UK would be less accepting of religion-based exclusion than would those residing in Saudi Arabia and that this finding would be magnified when considering outgroup exclusion (e.g., Brenick \& Killen, 2014). Second, we expected participants to be less accepting of excluding an ingroup than an outgroup member (e.g., Killen \& Rutland, 2011). Third, we hypothesized that mothers' judgments of exclusion would be associated with children's judgments with a larger effect size than those typically found (Degner \& Dalege, 2013) given the greater role of family and parents' authority in Middle Eastern countries (e.g., Al-Zahrani \& Kaplowitz, 1993). Additionally, we hypothesized that such a parentchild correlation would increase with age given the greater convergence in attitudes found between parents and older, as opposed to younger, children (Tenenbaum \& Leaper, 2002). In addition, we explored differences based on location of residence. Fourth, based on previous research on age differences (Killen \& Rutland, 2011), we expected older children to be less accepting of exclusion than younger children in both samples. Such a diminished acceptance of exclusion with age would be consistent with the greater parent-child association in acceptability ratings we hypothesized for older versus younger children as mothers overall should not be accepting of exclusion. Our final hypotheses examined reasoning. Based on Killen and Rutland's argument that social exclusion is often justified as a social conventional and personal choice rather than a moral issue, we expected that children and mothers residing in the UK would be more likely to invoke moral reasoning and less likely to invoke social conventional reasoning and psychological reasoning than would those residing in Saudi Arabia. Finally, we expected a relation between mothers and children in their reasoning overall.

\section{Method}

\section{Participants}

The sample size was determined based on previous, similar studies investigating parent-child dyads (e.g., Castelli et al., 2009; Degner \& Dalege, 2013). In total, 118 dyads participated: 60 Saudi children and their mothers residing in Saudi Arabia and 58 Saudi children and mothers residing in the United Kingdom. All children and mothers were born in Saudi Arabia and were practicing Muslims. For the sample residing in Saudi Arabia, the participants consisted of 20 children in grade $3(M=8.50, S D=0.51), 20$ children in grade $5(M=10.55$ years, $S D=0.51$ months $)$, and 20 children in grade $7(M=12.40, S D=0.50)$. Grade 3 and 5 are primary school in Saudi Arabia and grade 7 is intermediate school. Twenty-four children were boys, and 36 were girls. The mean age of the mothers was 41.33 years ( $S D=7.30$ months). Ninety-six percent of mothers were married, $3 \%$ were divorced, and $1 \%$ was widowed. Fortyfive percent of the mothers were employed outside the home, and the rest of the mothers were stay-at-home mothers. Of the mothers, $5 \%$ held a postgraduate degree, $38 \%$ had a university undergraduate degree, $45 \%$ had finished high school, and 12\% mothers had not finished high 
school. To recruit these families, the first author posted adverts on parenting websites frequently visited by Saudi families. The first author also contacted a number of Saudi families and sent emails explaining the research to them and asking for volunteer participants, and then asking them to refer friends and family. Mothers provided written permission and children provided verbal assent. The interviews took place in participants' homes.

For the UK sample, the participants consisted of 16 children in grade 4 ( $M=8.44$ years, $\mathrm{SD}=0.51$ months $), 25$ children in grade 6 ( $M=10.48$ years, $S D=0.51$ months), and 17 children in grade $8(M=12.35, S D=0.50)$. The children attended state schools in the UK. Children in grades 4 and 6 are in primary school and children in grade 8 are in secondary school. We recruited children from grades that served the same ages in the two countries. Children's ages in the two samples were not significantly different from each other, $F<1$. Twenty-eight children were girls, and 30 were boys. The mean age of the mothers was 35.68 years ( $S D=3.38$ months) and all of them were married. Forty-three out of the 58 mothers residing in the UK were students studying on Saudi-funded scholarships in British universities. The remaining 15 were in the UK because their husbands were studying on Saudi-funded scholarships in British universities. One of these mothers was studying in university in the UK. Sixty-nine percent of the mothers had worked when they lived in Saudi Arabia and were in the UK on scholarships funded by their employers. To recruit the participants, a number of Saudi students and Saudi clubs in the UK were contacted to explain the research to them and ask for volunteer participants. Sixty-three percent of mothers held a postgraduate degree, $30 \%$ had a university undergraduate degree, and five mothers had finished high school. Thus, this sample was better educated than the Saudi sample residing in Saudi Arabia, $F(1,116)=16.11$, $p<0.001, \eta_{\mathrm{p}}{ }^{2}=0.12$. Research suggests that education can decrease prejudice (Vogt, 1997) and has a stronger relationship with individuals' levels of prejudice than does parents' attitudes (Hello et al., 2004). For this reason, maternal education was used as a covariate in all analyses.

In Saudi Arabia, the Education Ministry offers annual scholarships for Saudi citizens to study abroad. In addition, some Saudi employers (e.g., universities) provide scholarships for teaching staff to earn degrees abroad. The Ministry pays for spouses to attend classes in the new country, which at least eight of the 15 mothers did. A point worth noting is that a precondition of a funded scholarship is an agreement to return to Saudi Arabia. All families planned to return to Saudi Arabia at the end of their studies. For this reason, we refer to them as migrants rather than immigrants.

Families had resided in the UK for a mean of 3.98 years $(S D=2.37$ years). All families had residing in the UK for a minimum of one calendar year and a maximum of eight years. Length of time in the UK did not correlate with any judgments or use of reasoning so it was not explored further.

\section{Materials}

Four vignettes consisting of short stories about exclusion were read to the children. In half of the vignettes, the perpetrator of the exclusion was the main character (father) and in the other half the perpetrator was a group of peers. The perpetrators of exclusion in the peer vignettes were outgroup members (non-Muslims) when the target was an ingroup member (Muslims), and ingroup members (Muslims) when the target was an outgroup member (non-Muslims). An example of the vignette is "A group of Muslim girls play in the park. Maria wants to play with them, but they say they do not want to play with her because she is not Muslim". See Table 1 for the exact wording of the other vignettes.

All participants were practicing Muslims so the ingroup was always Muslims. In contrast, the perpetrator of exclusion in the father vignettes was an adult ingroup member (the Muslim child's father) when the target was an outgroup (a non-Muslim child), while he was an outgroup member (a non-Muslim child's father) when the target was an ingroup (a Muslim child). In the Saudi educational system, teachers are the same gender as their students and thus, girls do not have male teachers. To make sure we were able to ask about men's authority, and still have a male authority figure, we asked about fathers rather than teachers.

There were two targets of exclusion based on religious group (Muslim versus non-Muslim). The target of exclusion and peers were gender-matched to the participant. Table 1 lists the exact wording of the vignettes. The order of the vignettes was counterbalanced. After each vignette, the children were asked whether or not it was ok to exclude a child on a scale from 1 (not at all ok) to 4 (ok a lot). Next, participants were asked an open-ended question to justify their judgments. The interviews were audiotaped and transcribed.

\section{Procedure}

The (blinded) granted the study "Saudi children's reasoning regarding exclusion based on religion" ethical approval (UEC/2015/041/FAHS). After obtaining maternal permission in written form and children's verbal consent, the children and mothers were interviewed separately and asked to answer all four vignettes for approximately $20 \mathrm{~min}$ in a quiet room at their home by a Saudi researcher (the first author). All children and mothers were interviewed in Arabic. Fathers were not present during interviews. Children were informed that the interviews would be audio 
recorded, confidential, and that there were no right or wrong answers. The answers of the open-ended question were transcribed and coded by the researcher and then entered into SPSS. These answers were used to complement and support the interpretation of the quantitative data analyses conducted for this study.

\section{Coding Categories}

The children's justifications of their acceptability scores were coded using a coding system adapted from Killen et al. (2002). This coding system has been used to analyse social reasoning in previous research (Killen et al., 2002; Killen \& Stangor, 2001; Møller \& Tenenbaum, 2011). The coding categories included moral (fairness, empathy, and integration), social conventional (group functioning, authority, social religious influence, and stereotypes), psychological (personal choice) reasons, and other. Each time participants invoked a category, it was coded a 1 in the data set and a 0 when it was not used. Thus, the coding scheme was not mutually exclusive. However, no participant used more than type of reasoning category (moral, social conventional, or psychological) for the same vignette. Table 2 gives examples of the coding in more detail.

\section{Reliability Coding}

First, the first author was trained on a different dataset to learn the coding scheme. Next, the first author read 20 transcripts to adjust the coding scheme. To check that the coding scheme was appropriate, ten transcripts were translated into English and checked by the second author. After discussion, a new subcategory (religious influence) was added to the social conventional category. Finally, the first author and an Arabic-speaking colleague from Saudi Arabia studying in the UK, who was blind to the hypotheses, coded 29\% (34 transcripts) of the interviews independently to attain inter-rater reliability. The overall Kappa was $K=$ 0.80 . According to Cohen (2016), values of 0.80 are considered a substantial level of agreement.

\section{Results}

For each of the major variables of interest, results are presented separately for judgments scores and reasoning because, although related, they tap into different constructs. Only main effects and interactions relevant to the test of our hypotheses are reported. For each vignette, acceptability scores could range from 1 (not at all ok) to 4 (ok a lot). We first examined children's and then mothers' judgment scores using analysis of covariance (ANCOVA) models. Second, we conducted a hierarchical logistic regression model to 
Table 2 Justification categories

\begin{tabular}{ll}
\hline Categories & Definition and Examples \\
\hline Moral & \\
Fairness & $\begin{array}{l}\text { Focus on fairness and equality. "They are equal, so they should allow to him } \\
\text { to play". } \\
\text { Focus on feelings of the individuals and caring about them. "Shame on girls to } \\
\text { exclude Maria. I feel that she is upset, sad, and crying". } \\
\text { Empathy }\end{array}$ \\
$\begin{array}{l}\text { Refers to wrongfulness of discrimination and consequences of prejudice. "It is } \\
\text { discrimination, children should play together and love each other to avoid } \\
\text { wars and problems". }\end{array}$ \\
$\begin{array}{l}\text { Social Conventional } \\
\text { Group function }\end{array}$ \\
$\begin{array}{l}\text { Need to make the group function well. "They should let Omar play with them. } \\
\text { It is better to have more members in case one of them is injured". }\end{array}$ \\
$\begin{array}{l}\text { Focus on parental jurisdiction, religious and governmental authority and } \\
\text { jurisdiction. "Maybe their fathers do not want them to play with this boy so if } \\
\text { they let him play, their fathers will get sad or punish them". } \\
\text { Related to influencing others. "They must allow Maria to play with them and } \\
\text { teach her Islam to be a real Muslim". } \\
\text { Appealing to stereotypes and labels attributed to an individual based on group } \\
\text { membership, "They do not let Reem play with them because they think all } \\
\text { influence }\end{array}$ \\
$\begin{array}{l}\text { Muslims are terrorists". } \\
\text { Stereotypes }\end{array}$ \\
$\begin{array}{l}\text { Fecus on the character's rights to individual preferences of prerogatives. "The } \\
\text { girls have a choice. They are free. They do not want to play with her". }\end{array}$ \\
\hline
\end{tabular}

examine the predictors of children's judgments using the child's binary answer across the four vignettes recoded from 1 (not at all ok) to 4 (ok a lot) to 0 not at all ok and 1 (all other responses). We also conducted Spearman ranks correlation coefficients to examine relations between mothers' and children's judgments on the individual reasons. Third, we examined children's reasoning using ANCOVA models. ANCOVA models were used to examine the justification data (moral vs. social conventional vs. psychological reasons). These procedures are preferable to log-linear analytical ones when analysing dichotomous and repeatedmeasures designs) and they can be used when the degrees of freedom for the error terms are greater than 40 (Lunney, 1970). Fuller explanations (Posada \& Wainryb, 2008; Wainryb et al., 2001) and uses of the procedure can be found in developmental studies (Malti et al., 2012; Tenenbaum \& Ruck, 2012). Finally, we examined relations between mothers' and children's use of reasons with correlation analyses. As reported in the method section, mothers residing in the UK had acquired more formal education than those residing in Saudi Arabia. For this reason, maternal education served as a covariate in all ANCOVA and regression analyses.

\section{Descriptive Analyses}

On average, children did not rate exclusion acceptable with a score of $2.00(S D=0.78)$. Mothers $(M=1.64, S D=0.74)$ were even less likely to support exclusion than were their children, $t(117)=800.81, p<0.001$, partial $\eta^{2}=0.87$. Figure 1 shows the mean judgment ratings for children, while Fig. 2 shows the mean judgments ratings for mothers.

\section{Acceptability of Exclusion Judgments}

\section{Children}

To examine the first set of hypotheses, we conducted a 2 (Vignette: Ingroup, Outgroup) $\times 2$ (Location: UK, Saudi Arabia) $\times 2$ (Perpetrator: Peer, Father $) \times 3($ Age: $8,10,12)$ mixed-design ANCOVA. Location and Age served as between-groups factors on children's judgments of the vignettes, and perpetrator and vignette served as withinsubjects factors. Maternal education served as a covariate. The mean judgments on whether it was ok to exclude served as the DV. There was no significant main effect of age, $F(2,111)=0.30, p=0.74$, partial $\eta^{2}=0.01$, nor were there significant interaction effects. There was no significant effect of vignette type, $F(1,111)=3.03, p=0.08$, partial $\eta^{2}=0.03$, nor of Perpetrator, $F(1,111)=3.59, p=0.06$, partial $\eta^{2}=0.03$. Maternal education was significantly related to children's judgments, $F(1,111)=10.47, p=$ 0.002 , partial $\eta^{2}=0.09$. A follow-up correlation suggested that the more education mothers had, the less likely children thought exclusion was acceptable, $r(116)=-0.43, p<$ 0.001. As hypothesized, after controlling for education, children residing in the UK $(M=1.18, S D=0.31)$ were less likely than those residing in Saudi Arabia $(M=2.00$, 
Children's Mean Exclusion Judgments

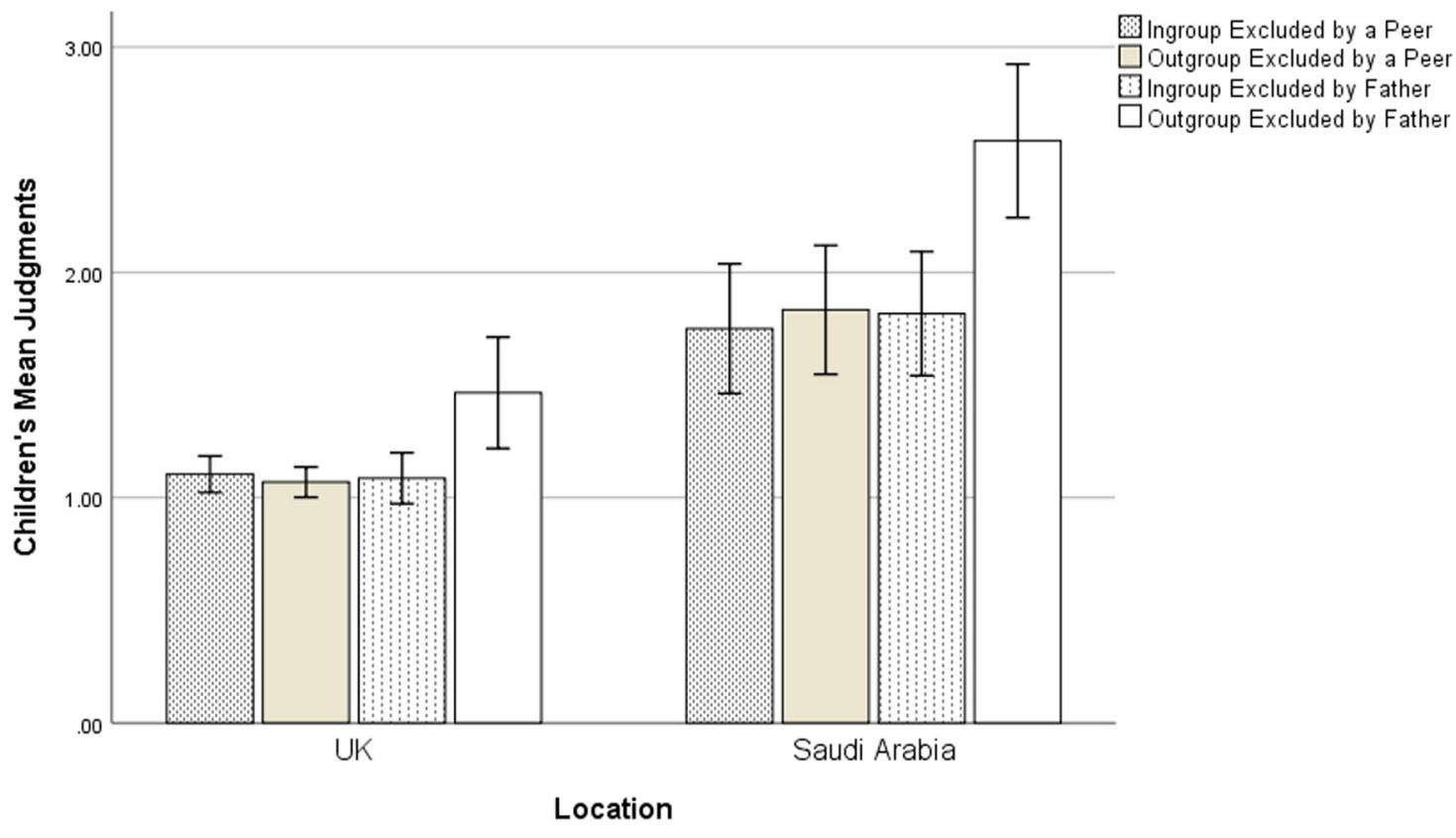

Error bars: $95 \% \mathrm{Cl}$

Fig. 1 Children's Mean Exclusion Judgments. $1=$ not at all ok, $2=$ a little bit not ok, $3=$ a little bit ok, $4=$ ok a lot. $N=58$ children residing in the UK and 60 residing in Saudi Arabia

\section{Mothers' Mean Exclusion Judgments}

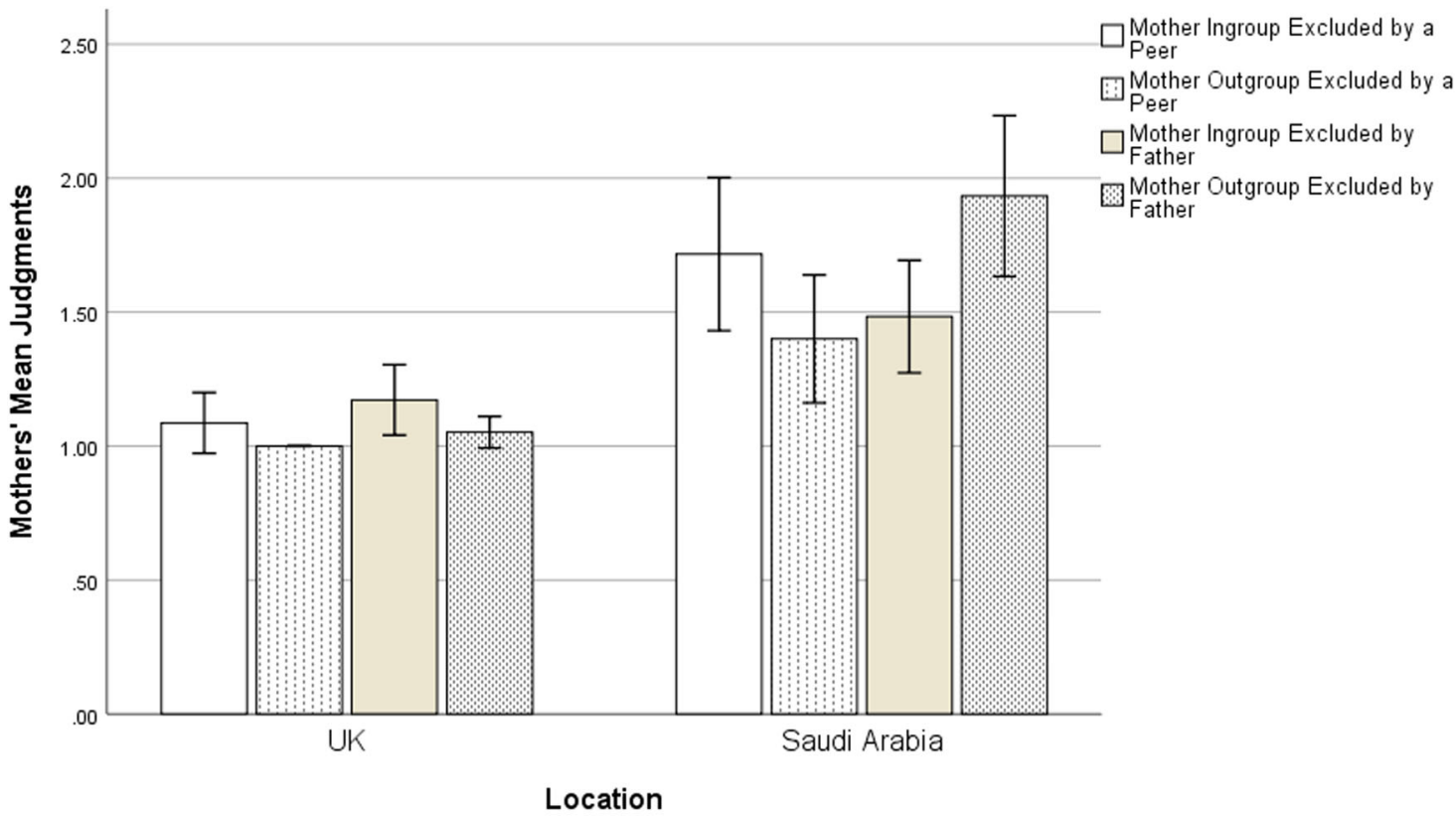

Error bars: $95 \% \mathrm{Cl}$

Fig. 2 Mothers' Mean Exclusion Judgments. $1=$ not at all ok, $2=$ a little bit not ok, $3=$ a little bit ok, $4=$ ok a lot. $N=58$ mothers residing in the UK and 60 residing in Saudi Arabia 
Table 3 Spearman rho's correlations between children's and mothers' judgments

\begin{tabular}{llllllll}
\hline & 2 & 3 & 4 & 5 & 6 & 7 & 8 \\
\hline 1. Child: Ingroup excluded by peer & $0.26^{* *}$ & $0.36^{* *}$ & $0.48^{* *}$ & $0.22^{* *}$ & 0.10 & 0.13 & $0.33^{* *}$ \\
2. Child: Outgroup excluded by peer & - & $0.34^{* *}$ & $0.35^{* *}$ & $0.32^{* *}$ & $0.34^{* *}$ & $0.27^{* *}$ & $0.35^{* *}$ \\
3. Child: Ingroup excluded by father & - & - & $0.27^{* *}$ & $0.20^{*}$ & 0.10 & $0.30^{* *}$ & $0.24^{*}$ \\
4. Child: Outgroup excluded by father & - & - & - & $0.39^{* *}$ & 0.17 & 0.12 & $0.32^{* *}$ \\
5. Mother: Ingroup excluded by peer & - & - & - & - & $0.41^{* *}$ & $0.32^{* *}$ & $0.48^{* *}$ \\
6. Mother: Outgroup excluded by peer & - & - & - & - & - & $0.39^{* *}$ & $0.48^{* *}$ \\
7. Mother: Ingroup excluded by father & - & - & - & - & - & - & $0.53^{* *}$ \\
8. Mother: Outgroup excluded by father & - & - & - & - & - & - & - \\
\hline
\end{tabular}

$* p<0.05 ; * * p<0.01 ; * * * p<0.001$
$S D=0.74)$ to report that exclusion was acceptable, $F(1$, $111)=41.09, p<0.0001$, partial $\eta^{2}=0.27$.

\section{Mothers}

Second, we conducted 2 (Vignette: Ingroup, Outgroup) $\times 2$ (Location: UK, Saudi Arabia) $\times 2$ (Perpetrator: Peer, Father) mixed-design ANCOVA on mothers' judgment ratings on vignettes, with location as the only between-group variable. There was no significant main effect of vignette, $F(1,111)$ $=1.37, p=0.25$, partial $\eta^{2}=0.01$, nor was there a main effect of Perpetrator, $F(1,111)=0.70, p=0.41$, partial $\eta^{2}$ $=0.01$. As expected, maternal education was related to mothers' judgments, $F(1,111)=4.19, p=0.04$, partial $\eta^{2}$ $=0.04$. A follow-up correlation suggested that the more education mothers had, the less likely mothers thought exclusion was acceptable, $r(116)=-0.31, p=0.001$. Similar to their children, after controlling for education, mothers residing in the UK $(M=1.08, S D=0.22)$ were less likely than those residing in Saudi Arabia $(M=1.63, S D=$ $0.78)$ to report that exclusion was acceptable, $F(1,111)=$ $18.11, p=0.001$, partial $\eta^{2}=0.14$. There was a statistically significant interaction of vignette by perpetrator, $F(1,111)$ $=4.76, p=0.03$, partial $\eta^{2}=0.04$. However, this effect was qualified by a statistically significant vignette by Perpetrator $\times$ Location interaction effect, $F(1,111)=9.12, p$ $=0.003$, partial $\eta^{2}=0.07$. To tease apart this interaction, we conducted 4 one-way repeated measures ANCOVA models controlling for education. We used 0.01 as the alpha to control for the multiple testing. The first two repeatedmeasures ANCOVA models examined whether mothers differed in their judgments of exclusion with peer as a perpetrator when the excluded child was an ingroup or outgroup member for mothers living in Saudi and the UK. There was no difference in judgments by mothers residing in the UK, $F(1,56)=0.74, p=0.39$, or Saudi Arabia, $F(1$, $58)=0.54, p=0.33$ on either of the comparison. Note that all mothers residing in the UK rated it as not ok at all when a Muslim peer excluded a non-Muslim peer. The next two repeated-measures ANCOVA models examined whether mothers differed in their judgments of exclusion with father as a perpetrator when the excluded child was an ingroup or outgroup member for mothers living in Saudi and the UK. Although there was no difference for mothers residing in the UK, $F(1,56)=0.42, p=0.52$, mothers residing in Saudi Arabia were less accepting of exclusion when a nonMuslim father excluded a Muslim child $(M=1.48, S D=$ $0.81)$ than when a Muslim father excluded a non-Muslim child $(M=1.93, S D=1.16), F(1,58)=6.86, p=0.01$, partial $\eta^{2}=0.11$.

\section{Relations between Children's and Mothers' Judgments}

Children's and mothers' judgments were not normally distributed, so we computed Spearman ranks correlation coefficients between mothers' and children's answers. Summed across the vignettes, mothers' and children's responses were positively correlated with a large effect size, $r(116)=0.53, p<0.0001$. We also conducted a Spearman ranks correlation on the individual vignettes. Table 3 displays these correlations, which indicates that children's and mothers' responses on the individual vignettes were significantly and positively correlated with each other.

We then looked at the predictors of children's judgments across the vignettes. When we added children's scores together across the judgments, 51 out of 118 children and 71 out of 118 mothers reported that it was never acceptable to exclude across all four vignettes. For this reason, we dichotomised children's and mothers' answers separately into whether they reported whether it was unacceptable to exclude on all the vignettes or not. We then conducted a logistic regression on children's binary responses. In the first step, maternal education was entered and was statistically reliable against a constant only model, $X^{2}(1)=14.18, p<0.001$. Children were less accepting of exclusion when their mothers had more 
Table 4 Predictors of children's judgments

\begin{tabular}{|c|c|c|c|c|c|c|c|c|}
\hline \multirow[t]{2}{*}{ Predictor } & \multicolumn{2}{|c|}{$\begin{array}{l}\text { Unstandar- } \\
\text { dised }\end{array}$} & \multirow[b]{2}{*}{ Wald $\left(\mathrm{z}^{2}\right)$} & \multirow[b]{2}{*}{ df } & \multirow[b]{2}{*}{$\begin{array}{l}\text { Significance } \\
(p \text { value })\end{array}$} & \multirow[b]{2}{*}{$\begin{array}{l}\text { Odds Ratio } \\
(\operatorname{Exp}(B))\end{array}$} & \multicolumn{2}{|c|}{$\begin{array}{l}95 \% \text { CI for } \\
\text { Odds Ratio }\end{array}$} \\
\hline & B & SE & & & & & Lower & Upper \\
\hline \multicolumn{9}{|l|}{ Step 1} \\
\hline Education & -0.93 & 0.25 & 14.18 & 1 & 0.0001 & 0.39 & 0.24 & 0.64 \\
\hline \multicolumn{9}{|l|}{ Step 2} \\
\hline Education & -0.69 & 0.33 & 4.43 & 1 & 0.04 & 0.50 & 0.27 & 0.95 \\
\hline Location & 1.92 & 0.53 & 13.14 & 1 & 0.0001 & 6.83 & 2.42 & 19.31 \\
\hline Mothers' Judgments & 1.57 & 0.60 & 6.88 & 1 & 0.009 & 4.78 & 1.49 & 15.41 \\
\hline $\begin{array}{l}\text { Mothers' Judgments by } \\
\text { Location }\end{array}$ & 1.02 & 1.16 & 0.77 & 1 & 0.38 & 2.77 & 0.28 & 26.99 \\
\hline $\begin{array}{l}\text { Mothers' } \\
\text { Judgments by Age }\end{array}$ & -0.02 & 0.023 & 0.54 & 1 & 0.46 & 0.98 & 0.93 & 1.04 \\
\hline Constant & -0.06 & 1.68 & 0.001 & 1 & 0.97 & 0.94 & & \\
\hline
\end{tabular}

Step $1 R^{2}=0.20$ (Nagelkerke). Model $\left.X^{2} \square 1\right)=18.61, p<0.0001$. Step $2 R^{2}=0.49$ (Nagelkerke). Model $\left.X^{2} \square 5\right)=53.25, p<0.0001$. Maternal Highest Level of Education Completed $(1=$ primary school, $2=$ intermediate school, $3=$ secondary school, $4=$ university, $5=$ some postgraduate education in addition to university)
Table 5 Spearman rho correlation coefficients between variables predicting children's judgments

\begin{tabular}{lllll}
\hline & 2 & 3 & 4 & 5 \\
\hline $\begin{array}{l}\text { 1. Children's judgment score } \\
\text { on the vignettes }\end{array}$ & $0.53^{* * * *}$ & -0.04 & $0.62^{* * *}$ & $-0.37 * * *$ \\
$\begin{array}{l}\text { 2. Mothers' judgment score } \\
\text { on the vignettes }\end{array}$ & - & 0.06 & $0.51^{* * *}$ & $-0.32^{* * * *}$ \\
$\begin{array}{l}\text { 3. Age in months } \\
\text { 4. Location }\end{array}$ & - & - & 0.10 & 0.02 \\
5. Education & - & - & - & $-0.31 * * *$ \\
\hline
\end{tabular}

$* p<0.05 ; * * p<0.01 ; * * * p<0.001$

education. Step 2, the addition of maternal judgments, location, the interaction term between maternal judgments and location, and the interaction term between maternal judgments and child age, improved the prediction of children's scores, $X^{2}(5)=53.25, p<0.001$. Maternal education continued to predict children's judgments in the model. In addition, children residing in the UK were less accepting of exclusion than children residing in Saudi Arabia. Mothers' scores on the vignettes predicted children's scores on the vignettes. The interaction terms of mothers' judgments by location and mothers' judgments by age were not statistically significant predictors. In other words, children's judgments were predicted by maternal education, location, and mothers' judgments. However, mothers' judgments were not moderated by location and or with the age of the child. Table 4 displays the significance levels and odd ratios. Table 5 displays the correlation coefficients.
Table 6 Mean number of times individual reasoning codes were used in the four vignettes

\begin{tabular}{lll}
\hline Reasoning & Child & Mother \\
\hline Fairness & $0.84(1.16)$ & $1.18(1.38)$ \\
Empathy & $0.77(1.04)$ & $0.17(0.40)$ \\
Integration & $0.27(0.71)$ & $0.77(1.03)$ \\
Group Functioning & $0.09(0.35)$ & $0.03(0.18)$ \\
Authority & $0.15(0.43)$ & $0.12(0.42)$ \\
Social/Religion influence & $0.90(1.28)$ & $0.82(1.03)$ \\
Stereotype & $0.01(0.09)$ & $0.13(0.38)$ \\
Psychological & $0.17(0.48)$ & $0.26(0.55)$ \\
Other & $0.85(1.10)$ & $0.52(0.72)$ \\
\hline
\end{tabular}

Fairness, empathy, and integration are subcategories of moral reasoning while group functioning, authority, social/religion influence, and stereotypes are subcategories of social conventional reasoning. Because each individual reason (moral or social conventional) was coded as present or absent, there are more underlying codes than moral or social conventional reasons. For example, if a participant invoked fairness and empathy for the same vignette, they would receive a 1 for moral reasons for that vignette rather than a 2. Standard deviations are in parentheses. $N=118$ children and mothers

\section{Type of Reason (Moral, Social Conventional, and Psychological)}

\section{Descriptive statistics}

Table 6 shows the mean number of times individual codes were used totalled across the vignettes. Table 7 shows the mean number of times the reasoning categories (moral, 
Table 7 Mothers' mean use of reason by vignette

\begin{tabular}{|c|c|c|c|c|c|c|}
\hline \multirow[b]{2}{*}{ Vignette } & \multicolumn{2}{|l|}{ Moral } & \multicolumn{2}{|c|}{ Social Conventional } & \multicolumn{2}{|l|}{ Moral } \\
\hline & UK & Saudi & UK & Saudi & UK & Saudi \\
\hline Muslim excluded by Peer & $0.86_{\mathrm{a}}(0.35)$ & $0.25_{\mathrm{b}}(0.44)$ & $0.04_{a}(0.18)$ & $0.53_{\mathrm{b}}(0.50)$ & $0.07(0.26)$ & $0.08(0.28)$ \\
\hline Non-Muslim excluded by Peer & $0.62(0.49)$ & $0.40(0.49)$ & $0.15(0.37)$ & $0.38(0.49)$ & $0.00(0.00)$ & $0.08(0.28)$ \\
\hline Muslim excluded by Father & $0.79_{\mathrm{a}}(0.41)$ & $0.35_{\mathrm{b}}(0.48)$ & $0.08(0.28)$ & $0.33(0.48)$ & $0.02 \mathrm{a}(0.13)$ & $0.15 b(0.36)$ \\
\hline Non-Muslim excluded by Father & $0.72_{\mathrm{a}}(0.45)$ & $0.27_{\mathrm{b}}(0.45)$ & $0.12_{\mathrm{a}}(0.33)$ & $0.52_{\mathrm{b}}(0.50)$ & $0.02(0.13)$ & $0.10(0.30)$ \\
\hline
\end{tabular}

Standard deviations are in parentheses. Different subscripts indicate that means are significantly different from each other for that reason (moral or social conventional) based on location with an alpha smaller than 0.006. $N=118$

social conventional, and psychological) were used by mothers and children separately by country of residence.

\section{Children}

To examine the second set of hypotheses, we conducted a 2 (Location: UK, Saudi Arabia) $\times 3$ (Age: 8, 10, 12) $\times 2$ (Vignette: Ingroup, Outgroup) $\times 2$ (Perpetrator: Peer, Father) $\times 3$ (Type of Reasoning: Moral, Social Conventional, Psychological) mixed-design ANCOVA. Vignette, perpetrator, and type of reasoning served as within-subject factors, and Location and Age served as between-groups factors on children's use of the types of reasoning (moral vs. social conventional vs. psychological). Maternal education served as a covariate. There was no statistically significant interaction between age and type of reason based on Greenhouse-Geisser tests, $F(3,158)=1.41, p=0.24$, partial $\eta^{2}=0.03$. As expected, there was a statistically significant Reason $\times$ Location interaction effect indicated by Greenhouse-Geisser tests, $F(1,111)=27.98, p<0.001$, partial $\eta^{2}=0.20$. To tease apart the interaction effect, we conducted three one-way ANCOVA models with type of reasoning (moral or social conventional) as a DV and location as an IV using an alpha of 0.025 (0.05 divided by two tests) to correct for multiple testing. Education again served as a covariate. Because we coded participants as using a category or not for each vignette separately and then we summed those scores, their total scores could range from 0 (never invoked) to 4 (invoked on all vignettes). As we hypothesized, across the four vignettes, children residing in the UK $(M=2.52, S D=1.14)$ were more likely to reference social exclusion as a moral issue than were children residing in Saudi Arabia $(M=1.25, S D=1.28), F(1,115)$ $=23.14, p<0.0001$, partial $\eta^{2}=0.17$. Relatedly, children residing in the UK $(M=0.43, S D=0.73)$ were less likely to reference social exclusion as a social conventional issue than were children residing in Saudi Arabia $(M=1.77, S D$ $=1.39), F(1,115)=31.11, p<0.0001$, partial $\eta^{2}=0.21$. In contrast, there was no difference in use of psychological reasoning based on location, $F(1,115)=0.41, p=0.53$.

\section{Mothers}

We conducted a 2 (Location: UK, Saudi Arabia) 2 (Vignette: Ingroup, Outgroup) $\times 2$ (Perpetrator: Peer, Father $) \times 3$ (Type of Reasoning: Moral, Social, Psychological) mixeddesign ANCOVA. Vignette, perpetrator, and type of reasoning served as within-subject factors, and Location served as between-groups factors on mothers' use of the types of reasoning (moral. social conventional, psychological). Maternal education served as a covariate. Similar to the analysis on children's responses, there was a significant Reason x Location interaction effect, $F(1,163)=45.12$, $p<0.0001$, partial $\eta^{2}=0.28$. To tease apart the interaction effect, we conducted two one-way ANCOVA models with type of reasoning (moral or social conventional) as a DV and location as an IV. Education again served as a covariate. We used 0.02 as the alpha to correct for multiple comparisons. As we hypothesized, across the four vignettes, mothers residing in the UK $(M=3.00, S D=0.99)$ were more likely to reference social exclusion as a moral issue than were mothers residing in Saudi Arabia $(M=1.27, S D$ $=1.23), F(1,115)=54.40, p<0.001$, partial $\eta^{2}=0.32$. Relatedly, mothers residing in the UK $(M=0.40, S D=$ 0.67 ) were less likely to reference social exclusion as a social conventional issue than were mothers residing in Saudi Arabia $(M=1.77, S D=1.29), F(1,115)=34.39$, $p<0.0001$, partial $\eta^{2}=0.23$. Similarly, mothers residing in the UK $(M=0.10, S D=0.31)$ were less likely to reference social exclusion as a psychological issue than were mothers residing in Saudi Arabia $(M=0.42, S D=0.67), F(1,115)$ $=12.89, p<0.0001$, partial $\eta^{2}=0.10$.

There was also a significant Type of Reason $\times$ Education interaction effect, $F(1,163)=5.96, p=0.008$, partial $\eta^{2}$ $=0.05$. Spearman ranks correlations indicated that the use of moral reasoning increased with increases in education, $r(116)=0.28, p=0.002$, whereas the use of social conventional reasoning decreased with increases of education, $r(116)=-0.36, p<0.001$. In contrast, there was no relation between education and psychological reasoning, $r$ $(116)=-0.10, p=0.91$. 


\section{Relations between Children's and Mothers' Reasoning}

To examine whether children's use of reasons was related to mothers' reasons across the vignettes, we tabulated the number of times mothers and children used moral, social conventional, and psychological reasoning across the four vignettes, which could range from 0 to 4 . The data were not normally distributed so we conducted a series of Spearman's rank correlations and chi-square tests.

Children's use of moral reasoning was positively associated with mothers' use of moral reasoning, $r(116)=0.37$, $p<0.0001$, and children's use of social conventional reasoning was positively associated with mothers' use of social conventional reasoning, $r(116)=0.46, p<0.0001$. In contrast, mothers' and children's use of psychological reasoning were uncorrelated, $r(116)=-0.07, p=0.43$.

\section{Discussion}

This study examined judgments and reasoning about religion-based peer exclusion in Saudi children and their mothers residing in the UK and in Saudi Arabia. This research supports the SRD theory by demonstrating that mothers and the cultural community in which children reside influence children's reasoning about exclusion. Similar to previous research (e.g., Alsamih \& Tenenbaum, 2018; Killen et al., 2002), mothers and children judged exclusion as wrong. Indeed, mothers and children in both Saudi Arabia and the UK did not accept exclusion.

The first hypothesis, which was that mothers and children residing in the UK would be less likely to accept exclusion, was supported. Second, we found support for the hypothesis that children's judgments and reasoning would be predicted by mothers' evaluations after controlling for the significant effect of maternal education. We also found partial support for our hypothesis that outgroup exclusion would be condemned more than ingroup exclusion, but only in that mothers residing in Saudi Arabia judged fathers' exclusion worse when an ingroup than an outgroup child was excluded. Finally, in contrast to our hypotheses, our age hypotheses were not supported. We did not find age differences in evaluations or reasoning. Nor did we find greater concordance between mothers and older children than between mothers and young children.

Overall, Saudi families residing in the UK were less accepting of peer exclusion than Saudi families in Saudi Arabia. As noted, the mothers differed in their levels of education in the two samples. Education has a liberalising effect on outgroup attitudes (Hello et al., 2006; Vogt, 1997), which may partially explain the differences between mothers. Collapsing across the samples, educational level did indeed account for a moderate degree of variation. Moreover, in the UK, the mothers were connected to university environments. As mentioned, these environments may be more accepting of outgroup differences than other environments.

In addition, mothers in Saudi Arabia were more accepting of exclusion when fathers excluded an outgroup member than an ingroup member. This finding suggests that these mothers may have had a higher level of ingroup favoritism than the mothers residing in the UK (Turner \& Reynolds, 2001). Mothers may also have been worried about the impact that such peers could have on their children in terms of following strict rules (Scourfield et al., 2010). Perhaps, this concern explains why mothers used more psychological reasoning in Saudi Arabia than the UK. Simply by being willing to move to the UK, we suspect that mothers residing in the UK would have been more liberal and less prejudiced in general than the mothers residing in Saudi Arabia. However, we did not measure attitudes prior to their move so we cannot be certain.

There are a host of reasons why we might have found that Saudi children in the UK were less accepting of exclusion than in Saudi Arabia. Unlike their mothers, the decision to move to the UK would not have been under the jurisdiction of the child. For that reason, we examine other explanations.

Across both groups of children, children's attitudes were predicted by mothers' attitudes. This finding is consistent with past research that has shown a relation between parents' and children's attitudes (Castelli et al., 2008; Castelli et al., 2009; Degner \& Dalege, 2013). Previous studies suggest that the time mothers spend with their children plays an important role in affecting children's attitudes and behaviours (Castelli et al., 2008; Castelli et al., 2009). The correlation between mothers' and children's judgments was large and the correlation for the number of reasons was medium. In contrast, Degner and Dalege found a medium effect between children's and mothers' outgroup attitudes in their meta-analysis. The size of the effect on judgements suggests that research with non-Western cultures may underestimate the effect of parents on children's outgroup attitudes. In Saudi culture, mothers spend a good deal of time with children. Indeed, Saudi culture is a familyoriented culture in which mothers take the primary responsibility for child care (Almalki, 2020).

Although the relation between children's and mothers' judgments was large, there is still variance that needs to be accounted for. Another reason children in the UK may have been less accepting is that individuals often adjust their behaviours to reflect the host culture with regard to interaction with others (Berry, 1997, 2005; Bornstein \& Cote, 2006; Patel et al., 1996; Rueschenberg \& Buriel, 1989; Gratier, 2003). As a result of living in a multicultural 
society in terms of religion, such as the UK, the Saudi children in the UK may have become more tolerant and willing to accept peers from different backgrounds.

Second, the Saudi children in the UK may have been less biased towards outgroup members because of contact with individuals from different cultural and religious backgrounds compared with the families residing in Saudi Arabia. Based on intergroup contact theory, contact with outgroup members can reduce prejudice against outgroup members (Allport 1954; Pettigrew \& Tropp, 2008; Tadmor et al., 2012). The Saudi children residing in the UK attend British state sector schools where they have a high level of interaction with outgroup members (i.e., non-Muslims). Some children and their mothers mentioned that their own contact with individuals from different groups in the UK motivated them to judge religion-based exclusion as unacceptable. For example, a 10-year-old boy said, "There is no problem playing with others. I have non-Muslim friends, we play together in school, we work together, and we prepare our presentations together. It is normal". Allport (1954) suggested that interaction with outgroup members provides knowledge about outgroup members, which reduces bias. Such contact may decrease feelings of threat. In their review of tolerance, Verkuyten and Killen (2021) suggest that tolerance of others increases along with decreases of threat.

As noted by many, however, not all contact is positive (Bagci \& Gungor, 2019; Barlow et al., 2012; Graf \& Paolini, 2016; Visintin et al., 2017). Having had negative contact as a minority member, however, may lead participants to be less accepting of exclusion. In exclusion scenarios in previous studies, minority participants identified themselves with the victim of exclusion, whereas the majority identified itself with the excluder (Dovidio et al., 2002). This in turn motivates the minority to show less acceptance of exclusion, based on their own experience of victimization. As a minority, Saudis in the UK may face religion-based exclusion and prejudice in the UK, so they became more sensitive to exclusion. A mother of a 12-yearold Saudi boy in the north of the UK said, "These scenarios happen to my son, so he hates going to the school, a group of his peers were calling him [Bin Laden] and he came back home and asked who is he [Bin Laden] and why do my peers call me that?" One limitation is, of course, that we did not explicitly measure intergroup contact.

When reasoning about exclusion, children residing in the UK tended to justify peer exclusion using moral issues more than did families in Saudi Arabia, supporting our final set of hypotheses. The former families were also less likely to perceive social exclusion as a social conventional issue than were families residing in Saudi Arabia. Young people in Western societies typically use moral reasons when condemning exclusion (Tenenbaum et al., 2018; Theimer et al., 2001).
Moving to the UK may have caused the children to re-evaluate their conception of social exclusion.

Age, in contrast, did not account for any of the variance in predicting children's judgments or reasoning. Sometimes young children condemn exclusion more than do older children (Tenenbaum et al., 2018) because of older children's acceptance of societal systems that lead to segregation. Yet we did not find increased social conventional reasoning with the older age groups nor more nuanced reasoning, which is often found in older more than younger children (Killen \& Rutland, 2011). At the same time, there are few differences in outgroup bias overall across these age groups (Raabe \& Beelmann, 2011). Age also did not serve as a moderator of the relation between mothers' and children's judgments. It may be that we needed an even larger difference in age groups to find an effect. Future research should explore these questions with a larger age range to see how the development of outgroup bias and reasoning develops in these age groups.

\section{Limitations and Future Research}

Although the current study contributes to debates on contextual understanding of exclusion, there are limitations. The first is that most of the mothers who chose to reside in the UK so that they or their husbands could study in the UK had higher levels of education and were probably more tolerant to begin with. However, this does not discount that children residing in the UK were more condemning of exclusion than their Saudi counterparts. If anything, it points to a protective factor against the development of exclusionary beliefs. Thus, these findings answer questions about how cultural communities influence parents' beliefs and how these beliefs are related to children's beliefs (Bornstein et al., 2012). We recommend more future research to take into account parents' education (high, low) as a variable in the design.

Second, we did not interview fathers because the researcher was female and contact between non-familial women and men is not acceptable in Saudi society. In fact, the fathers chose not to be at home when the female researcher visited. However, as previously mentioned, mothers are primarily responsible for raising children in Saudi Arabia (Almalki, 2020). To compare the relative importance of mothers and fathers, future research should include fathers. Another limitation is that we did not ask for mothers to report their experiences with intergroup contact. Contact is related to how young people evaluate exclusion (Crystal et al., 2008). Although we did not explicitly ask about contact, about $20 \%$ of mother-child dyads in the UK sample spontaneously mentioned positive contact in the interviews. This study would have been strengthened had 
we assessed quality (positive and negative) and quantity of intergroup contact.

Although the families residing in the UK were generally less accepting of exclusion, the current study did not find a significant relation between Saudi families in the UK in their judgment of exclusion based on the length of staying in the UK. One reason may be that before allowing students to go abroad, students attend an induction week highlighting the importance of accepting others from different backgrounds, which may have a strong influence on individuals. Future research should test the effects of these types of induction programmes on participants' attitudes. Future research should also study Saudi children who attend international schools in Saudi Arabia where they have peers from different religious backgrounds and examine the intergroup contact in relation to peer exclusion. Such a school environment could be used as a comparison to the Saudi children studying in British schools. Finally, given the current goals of the Saudi government for a more inclusive and modern society (e.g. Saudi Vision, 2030), it would be good to examine whether families remain inclusive after returning to Saudi Arabia.

\section{Conclusion and Implications}

This study provides a novel perspective on children's acceptability and reasoning about religion-based exclusion by comparing the judgments of participants from a nonWestern culture (Saudi Arabia) both in their country of origin and in a new country of residence (the UK). This study extends research from the SRD theory on peer exclusion by also showing that mothers' judgments influence children's evaluations and conceptions of peer exclusion based on religion. The results of this study show that individuals' judgments and reasoning are embedded within the socio-cultural values of the country of residence and their own particular life histories and experiences (e.g., education level).

From a practical perspective, we need to find ways to prevent exclusion given that chronic exclusion can lead to the deleterious effect of resignation (Marinucci \& Riva, 2021a, 2021b). Our naturally occurring experiment provides preliminary evidence that different types of interventions (e.g., intergroup contact, anti-discrimination laws) at different system levels (e.g., school, governmental) may converge in decreasing acceptance of peer exclusion. Our findings provide suggestions that positive intergroup contact, more inclusive parental attitudes, higher levels of education, anti-discriminatory laws, and multiculturalism may facilitate a more accepting, inclusive, and tolerant society.
Acknowledgements We would like to thank (Blinded) for helpful discussions and for reading an earlier draft of this manuscript.

\section{Compliance with Ethical Standards}

Conflict of Interest The authors declare no competing interests.

Ethical Approval This study does not contain any studies involving animals. All procedures performed in studies involving human participants were in accordance with the ethical standards of University of Surrey (UEC/2015/041/FAHS) and with the 1964 Helsinki declaration and its later amendments or comparable ethical standards.

Informed Consent Informed consent was obtained from all individual participants included in the study.

Publisher's note Springer Nature remains neutral with regard to jurisdictional claims in published maps and institutional affiliations.

Open Access This article is licensed under a Creative Commons Attribution 4.0 International License, which permits use, sharing, adaptation, distribution and reproduction in any medium or format, as long as you give appropriate credit to the original author(s) and the source, provide a link to the Creative Commons license, and indicate if changes were made. The images or other third party material in this article are included in the article's Creative Commons license, unless indicated otherwise in a credit line to the material. If material is not included in the article's Creative Commons license and your intended use is not permitted by statutory regulation or exceeds the permitted use, you will need to obtain permission directly from the copyright holder. To view a copy of this license, visit http://creativecommons. org/licenses/by/4.0/.

\section{References}

Abrams, D., \& Rutland, A. (2008). The development of subjective group dynamics. In S. Levy \& M. Killen (Eds.), Intergroup Attitudes and Relations in Childhood through Adulthood. (pp. 3-15). Oxford University Press.

Abrams, D., Rutland, A., Pelletier, J., \& Ferrell, J. M. (2009). Children's group nous: Understanding and applying peer exclusion within and between groups. Child Development, 80(1), 224-243. https://doi.org/10.1111/j.1467-8624.2008.01256.x.

Allport, G. W. (1954). The Nature of Prejudice. Addison-Welsley

Almalki, S. (2020). Parenting Practices in Saudi Arabia: Gender-Role Modeling. In B. K. Ashdown \& A. N. Faherty (Eds.), Parents and Caregivers Across Cultures: Positive Development from Infancy Through Adulthood (pp. 231-246). Springer International Publishing. https://doi.org/10.1007/978-3-030-35590-6_16

Al-Rasheed, M. (2013). A most masculine state: Gender, politics and religion in Saudi Arabia. Cambridge University Press. https://doi. org/10.1017/CBO9781139015363

Alsamih, M., \& Tenenbaum, H. R. (2018). Saudi Arabian children's reasoning about religion based exclusion. British Journal of Developmental Psychology, 36(3), 508-513. https://doi.org/10. 1111/bjdp.12238.

Al-Simadi, F., \& Atoum, A. (2000). Family environment and selfconcept of Palestinian youth living in Jordanian refugee camps. Social Behaviour and Personality: An International Journal, 28 (4), 377-385. https://doi.org/10.2224/sbp.2000.28.4.377.

Al-Zahrani, S. S., \& Kaplowitz, S. A. (1993). Attributional biases in individualistic and collectivistic cultures: a comparison of 
Americans with Saudis. Social Psychology Quarterly, 56(3), 223-233. https://doi.org/10.2307/2786780.

Bagci, S. C., \& Gungor, H. (2019). Associations between perceived positive and negative parental contact and adolescents' intergroup contact experiences. International Journal of Intercultural Relations, 69, 76-86. https://doi.org/10.1016/j.ijintrel. 2019.01.002.

Barlow, F. K., Paolini, S., Pedersen, A., Hornsey, M. J., Radke, H. R., Harwood, J., Rubin, M., \& Sibley, C. G. (2012). The contact caveat: negative contact predicts increased prejudice more than positive contact predicts reduced prejudice. Personality and Social Psychology Bulletin, 38(12), 1629-1643. https://doi.org/ 10.1177/0146167212457953.

Bar-Tal, D. (1996). Development of social categories and stereotypes in early childhood: The case of "The Arab" concept formation, stereotype and attitudes by Jewish children in Israel. International Journal of Intercultural Relations, 20(3-4), 341-370. https://doi. org/10.1016/0147-1767(96)00023-5.

Bernstein, M. J., Sacco, D. F., Young, S. G., Hugenberg, K., \& Cook, E. (2010). Being "in" with the in-crowd: the effects of social exclusion and inclusion are enhanced by the perceived essentialism of ingroups and outgroups. Personality and Social Psychology Bulletin, 36(8), 999-1009. https://doi.org/10.1177/ 0146167210376059.

Berry, J. W. (1997). Immigration, acculturation and adaptation. Applied Psychology, 46(1), 5-68. https://doi.org/10.1111/j.14640597.1997.tb01087.x.

Berry, J. W. (2005). Acculturation: living successfully in two cultures. International Journal of Intercultural Relations, 29(6), 697-712. https://doi.org/10.1016/j.ijintrel.2005.07.013.

Bornstein, M. H., \& Cote, L. R. (2006). Parenting cognitions and practices in the acculturative process. In M. H. Bornstein \& L. R Cote (Eds.), Acculturation and Parent-Child relationships: Measurement and Development (pp. 173-196). Lawrence Erlbaum Associates Publishers. https://doi.org/10.4324/9780415963589

Bornstein, M. H., Cote, L. R., Haynes, O. M., Suwalsky, J. T., \& Bakeman, R. (2012). Modalities of infant-mother interaction in Japanese, Japanese American immigrant, and European American dyads. Child Development, 83(6), 2073-2088. https://doi.org/10. 1111/j.1467-8624.2012.01822.x.

Brenick, A., \& Killen, M. (2014). Moral judgments about Jewish-Arab intergroup exclusion: the role of cultural identity and contact. Developmental Psychology, 50(1), 86-99. https://doi.org/10. 1037/a0034702.

Brenick, A., Lawrence, S. E., Carvalheiro, D., \& Berger, R. (2019). Teaching tolerance or acting tolerant? Evaluating skills-and contact-based prejudice reduction interventions among Palestinian-Israeli and Jewish-Israeli youth. Journal of School Psychology, 75, 8-26. https://doi.org/10.1016/j.jsp.2019.07.001.

Brenick, A., \& Romano, K. (2016). Perceived peer and parent outgroup norms, cultural identity, and adolescents' reasoning about peer intergroup exclusion. Child Development, 87(5), 1392-1408. https://doi.org/10.1111/cdev.12594.

Brenick, A., Killen, M., Lee-Kim, J., Fox, N., Leavitt, L., Raviv, A., Masalha, S., Murra, F., \& Al-Smadi, Y. (2010). Social understanding in young Israeli-Jewish, Israeli Palestinian, Palestinian, and Jordanian children: Moral judgments and stereotypes. Early Education and Development, 21(6), 886-911. https://doi.org/10. 1080/10409280903236598.

Buhs, E. S., \& Ladd, G. W. (2001). Peer rejection as antecedent of young children's school adjustment: an examination of mediating processes. Developmental Psychology, 37(4), 550-560. https:// doi.org/10.1037/0012-1649.37.4.550.

Buhs, E. S., Ladd, G. W., \& Herald, S. L. (2006). Peer exclusion and victimization: processes that mediate the relation between peer group rejection and children's classroom engagement and achievement? Journal of Educational Psychology, 98(1), 1-13. https://doi.org/10.1037/0022-0663.98.1.1.

Castelli, L., De Dea, C., \& Nesdale, D. (2008). Learning social attitudes: children's sensitivity to the nonverbal behaviors of adult models during interracial interactions. Personality and Social Psychology Bulletin, 34(11), 1504-1513. https://doi.org/10.1177/ 0146167208322769.

Castelli, L., Zogmaister, C., \& Tomelleri, S. (2009). The transmission of racial attitudes within the family. Developmental Psychology, 45(2), 586-591. https://doi.org/10.1037/a0014619.

Crystal, D. S., Killen, M., \& Ruck, M. (2008). It is who you know that counts: Intergroup contact and judgments about race-based exclusion. British Journal of Developmental Psychology, 26(1), 51-70. https://doi.org/10.1348/026151007X198910.

Cohen, J. (2016). A Coefficient of Agreement for Nominal Scales. Educational and Psychological Measurement, 20(1), 37-46. https://doi.org/10.1177/001316446002000104.

Degner, J., \& Dalege, J. (2013). The apple does not fall far from the tree, or does it? A meta-analysis of parent-child similarity in intergroup attitudes. Psychological Bulletin, 139(6), 1270-1304. https://doi.org/10.1037/a0031436.

Dovidio, J. F., Kawakami, K., \& Gaertner, S. L. (2002). Implicit and explicit prejudice and interracial interaction. Journal of Personality and Social Psychology, 82(1), 62-68. https://doi.org/10. 1037/0022-3514.82.1.62.

Fayant, M. P., Muller, D., Hartgerink, C. H. J., \& Lantian, A. (2014). Is ostracism by a despised outgroup really hurtful? a replication and extension of Gonsalkorale and Williams (2007). Social Psychology, 45(6), 489-494. https://doi.org/10.1027/1864-9335/a 000209.

Gonsalkorale, K., \& Williams, K. D. (2007). The KKK won't let me play: Ostracism even by a despised outgroup hurts. European Journal of Social Psychology, 37(6), 1176-1186. https://doi.org/ 10.1002/ejsp.392.

Goodwin, S. A., Williams, K. D., \& Carter-Sowell, A. R. (2010). The psychological sting of stigma: the costs of attributing ostracism to racism. Journal of Experimental Social Psychology, 46(4), 612-618. https://doi.org/10.1016/j.jesp.2010.02.002.

Gorodzeisky, A. (2013). Mechanisms of exclusion: attitudes toward allocation of social rights to out-group population. Ethnic and Racial Studies, 36(5), 795-817. https://doi.org/10.1080/ 01419870.2011 .631740$.

Graf, S., \& Paolini, S. (2016). Investigating positive and negative intergroup contact: rectifying a long-standing positivity bias in the literature. In L. Vezzal \& S. Stathi (Eds), Intergroup Contact Theory: Recent developments and future directions. (pp. 100-121): Routledge.

Gratier, M. (2003). Expressive timing and interactional synchrony between mothers and infants: Cultural similarities, cultural differences, and the immigration experience. Cognitive Development, 18(4), 533-554. https://doi.org/10.1016/j.cogdev.2003.09.009.

Guan, X., \& Li, X. (2017). A cross-cultural examination of family communication patterns, parent-child closeness, and conflict styles in the United States, China, and Saudi Arabia. Journal of Family Communication, 17(3), 223-237. https://doi.org/10.1080/ 15267431.2017.1293062.

Hello, E., Scheepers, P., \& Sleegers, P. (2006). Why the more educated are less inclined to keep ethnic distance: an empirical test of four explanations. Ethnic and Racial Studies, 29(5), 959-985. https://doi.org/10.1080/01419870600814015.

Hello, E., Scheepers, P., Vermulst, A., \& Gerris, J. R. (2004). Association between educational attainment and ethnic distance in young adults: socialization by schools or parents? Acta Sociologica, 47(3), 253-275. https://doi.org/10.1177/0001699304046222.

Killen, M., \& Rutland, A. (2011). Children and Social Exclusion: Morality, Prejudice, and Group Identity. John Wiley \& Sons. 
Killen, M., \& Stangor, C. (2001). Children's social reasoning about inclusion and exclusion in gender and race peer group contexts. Child Development, 72(1), 174-186. https://doi.org/10.1111/ 1467-8624.00272.

Killen, M., Elenbaas, L., Rizzo, M. T., \& Rutland, A. (2017). The role of group processes in social exclusion and resource allocation decisions. In A. Rutland, D. Nesdale \& C. Spears Brown (Eds.), The Wiley handbook of group processes in children and adolescents (pp. 101-123). Wiley-Blackwell. https://doi.org/10.1002/ 9781118773123.ch5.

Killen, M., Elenbaas, L., \& Rutland, A. (2015). Balancing the fair treatment of others while preserving group identity and autonomy. Human Development, 58(4-5), 253-272. https://doi.org/10. $1159 / 000444151$.

Killen, M., Lee-Kim, J., McGlothlin, H., \& Stangor, C. (2002). How children and adolescents evaluate gender and racial exclusion. Monograph of the Society of Research in Child Development, 67 (4), I-129. https://www.jstor.org/stable/3181568.

Ladd, G. W., Herald-Brown, S. L., \& Reiser, M. (2008). Does chronic classroom peer rejection predict the development of children's classroom participation during the grade school years? Child Development, 79(4), 1001-1015. https://doi.org/10.1111/j.14678624.2008.01172.x.

Lunney, G. H. (1970). Using analysis of variance with a dichotomous dependent variable: An empirical study. Journal of Educational Measurement, 7(4), 263-269. https://doi.org/10.1111/j.17453984.1970.tb00727.x.

Malti, T., Killen, M., \& Gasser, L. (2012). Social judgments and emotion attributions about exclusion in Switzerland. Child Development, 83(2), 697-711. https://doi.org/10.1111/j.14678624.2011.01705.x.

Matthiesen, T. (2015). The domestic sources of Saudi foreign policy: Islamists and the state in the wake of the Arab Uprisings. Brookings Institution.

Marinucci, M., \& Riva, P. (2021a). Surrendering to social emptiness: Chronic social exclusion longitudinally predicts resignation in asylum seekers. British Journal of Social Psychology. https://doi. org/10.1111/bjso.12410 In press

Marinucci, M., \& Riva, P. (2021b). How intergroup social connections shape immigrants' responses to social exclusion. Group Processes \& Intergroup Relations. https://doi.org/10.1177/1368430219894620 In press

Metz, H. C. (1993). Saudi Arabia: A Country Study. Library of Congress

Mistry, J., Li, J., Yoshikawa, H., Tseng, V., Tirrell, J., Kiang, L., \& Wang, Y. (2016). An integrated conceptual framework for the development of Asian American children and youth. Child Development, 87(4), 1014-1032. https://doi.org/10.1111/cdev.12577.

Møller, S. J., \& Tenenbaum, H. R. (2011). Danish majority children's reasoning about exclusion based on gender and ethnicity. Child Development, 82(2), 520-532. https://doi.org/10.1111/j.14678624.2010.01568.x

Nesdale, D. (2004). Social identity processes and children's ethnic prejudice. In: M. Bennett \& F. Sani (Eds), The development of the social self (pp. 219-246). London: Psychology Press.

Nevo, J. (1998). Religion and national identity in Saudi Arabia. Middle Eastern Studies, 34(3), 34-53. https://www.jstor.org/ stable/4283951.

Nielsen, M., Haun, D., Kärtner, J., \& Legare, C. H. (2017). The persistent sampling bias in developmental psychology: a call to action. Journal of Experimental Child Psychology, 162, 31-38. https://doi.org/10.1016/j.jecp.2017.04.017.

Patel, N., Power, T. G., \& Bhavnagri, N. P. (1996). Socialization values and practices of Indian immigrant parents: correlates of modernity and acculturation. ChildDevelopment, 67(2), 302-313. https://doi.org/10.1111/j.1467-8624.1996.tb01735.x.
Pedersen, S., Vitaro, F., Barker, E. D., \& Borge, A. I. (2007). The timing of Middle-Childhood peer rejection and friendship: linking early behavior to early-adolescent adjustment. Child Development, 78(4), 1037-1051. https://doi.org/10.1111/j.1467-8624. 2007.01051.x.

Pettigrew, T. F., \& Tropp, L. R. (2008). How does intergroup contact reduce prejudice? Meta-analytic tests of three mediators. European Journal of Social Psychology, 38(6), 922-934. https://doi. org/10.1002/ejsp.504.

Phillips, D., Curtice, J., Phillips, M. \& Perry, J. (eds.) (2018). British Social Attitudes: The 35th Report. London: The National Centre for Social Research. http://www.bsa.natcen.ac.uk/media/39284/ bsa35_full-report.pdf.

Posada, R., \& Wainryb, C. (2008). Moral development in a violent society: Colombian children's judgments in the context of survival and revenge. Child Development, 79(4), 882-898. https:// doi.org/10.1111/j.1467-8624.2008.01165.x.

Prinstein, M. J., \& Aikins, J. W. (2004). Cognitive moderators of the longitudinal association between peer rejection and adolescent depressive symptoms. Journal of Abnormal Child Psychology, 32(2), 147-158. https://doi.org/10.1023/B:JACP.0000019767.55592.63.

Raabe, T., \& Beelmann, A. (2011). Development of ethnic, racial, and national prejudice in childhood and adolescence: a multinational meta-analysis of age differences. Child Development, 82(6), 1715-1737. https://doi.org/10.1111/j.1467-8624.2011.01668.x.

Rueschenberg, E., \& Buriel, R. (1989). Mexican American family functioning and acculturation: a family systems perspective. Hispanic Journal of Behavioral Sciences, 11(3), 232-244. https:// doi.org/10.1177/07399863890113002.

Rutland, A., \& Killen, M. (2017). Fair resource allocation among children and adolescents: the role of group and developmental processes. Child Development Perspectives, 11(1), 56-62. https:// doi.org/10.1111/cdep.12211.

Sacco, D. F., Bernstein, M. J., Young, S. G., \& Hugenberg, K. (2014). Reactions to social inclusion and ostracism as a function of perceived in-group similarity. Group Dynamics, 18(2), 129-137. https://doi.org/10.1037/gdn0000002.

Scourfield, J., Gilliat-Ray, S., Khan, A., \& Otri, S. (2010). Muslim childhood: Religious Nurture in a European Context. Oxford, UK: Oxford University Press.

Smetana, J. G. (2013). Moral development: The Social Domain Theory view. In P. D. Zelazo (Ed.), The Oxford Handbook of Developmental Psychology, Vol. 1: Body and Mind (pp. 832-863). https://doi.org/10.1093/oxfordhb/9780199958450.013. 0029

Smetana, J. G., Jambon, M., \& Ball, C. (2014). The social domain approach to children's social and moral judgments. In M. Killen \& J. Smetana (Eds.), Handbook of Moral Development (pp. 2345). Psychology Press.

Smith, A., \& Williams, K. D. (2004). R u there? Ostracism by cell phone text messages. Group Dynamics, 8(4), 291-301. https:// doi.org/10.1037/1089-2699.8.4.291.

Tadmor, C. T., Hong, Y. Y., Chao, M. M., Wiruchnipawan, F., \& Wang, W. (2012). Multicultural experiences reduce intergroup bias through epistemic unfreezing. Journal of Personality and Social Psychology, 103(5), 750-772. https://doi.org/10.1037/a0029719.

Tajfel, H. (1970). Experiments in intergroup discrimination. Scientific American, 223, 96-102.

Tajfel, H. and Turner, J. C. (1985). The social identity theory of intergroup behaviour. In: S. Worchel \& W. G. Austin, (Eds), Psychology of Intergroup Relations, 2nd Edition, (pp. 7-24). Nelson Hall, Chicago.

Tamis-LeMonda, C. S., Way, N., Hughes, D., Yoshikawa, H., Kalman, R. K., \& Niwa, E. Y. (2008). Parents' goals for children: the dynamic coexistence of individualism and collectivism in cultures 
and individuals. Social Development, 17(1), 183-209. https://doi. org/10.1111/j.1467-9507.2007.00419.x.

Tenenbaum, H. R., \& Leaper, C. (2002). Are parents' gender schemas related to their children's gender-related cognitions?: a meta analysis. Developmental Psychology, 38(4), 615-630. https://doi. org/10.1037/0012-1649.38.4.615.

Tenenbaum, H. R., \& Ruck, M. D. (2012). British Adolescents' and Young Adults' Understanding and Reasoning About the Religious and Nonreligious Rights of Asylum-Seeker Youth. Child Development, 83(3), 1102-1115. https://doi.org/10.1111/j.14678624.2012.01755.x.

Tenenbaum, H. R., Leman, P. J., Aznar, A., Duthie, R., \& Killen, M. (2018). Young people's reasoning about exclusion in novel groups. Journal of Experimental Child Psychology. Journal of Experimental Child Psychology, 175, 1-16. https://doi.org/10. 1016/j.jecp.2018.05.014.

Theimer, C. E., Killen, M., \& Stangor, C. (2001). Young children's evaluations of exclusion in gender-stereotypic peer contexts. Developmental Psychology, 37(1), 18-27. https://doi.org/10. 1037/0012-1649.37.1.18.

Tobia, V., Riva, P., \& Caprin, C. (2017). Who are the children most vulnerable to social exclusion? The moderating role of selfesteem, popularity, and nonverbal intelligence on cognitive performance following social exclusion. Journal of Abnormal Child Psychology, 45(4), 789-801. https://doi.org/10.1007/s10802-0160191-3.

Turiel, E. (1998). The development of morality. In W. Damon \& N. Eisenderg (Eds.), Handbook of child psychology: Socail. Emothional and personality development (5th ed., Vol, 3 PP. 863-932). Wiley.
Turiel, E., \& Wainryb, C. (2000). Social life in cultures: Judgments, conflict, and subversion. Child Development, 71(1), 250-256. https://doi.org/10.1111/1467-8624.00140.

Turner, J. C., Reynolds, K. J. (2001). The social identity perspective in intergroup relations: theories, themes, and controversies. In R. Brown \& S. Gaertner (Eds). Blackwell Handbook of Social Psychology: Intergroup Processes. (pp. 133-152). Blackwell. https://doi.org/10.1002/9780470693421.ch7

Verkuyten, M., \& Killen, M. (2021). Tolerance, dissenting beliefs, and cultural diversity. Child Development Perspectives. https://doi. org/10.1111/cdep.12399 In press

Visintin, E. P., Green, E. G., Pereira, A., \& Miteva, P. (2017). How positive and negative contact relate to attitudes towards Roma: Comparing majority and high-status minority perspectives. Journal of Community \& Applied Social Psychology, 27(3), 240-252. https://doi.org/10.1002/casp.2309.

Vogt, W. P. (1997). Tolerance \& education: Learning to live with diversity and difference: Sage Publications, Inc.

Wainryb, C., \& Turiel, E. (1994). Dominance, subordination, and concepts of personal entitlements in cultural contexts. Child Development, 65(6), 1701-1722. https://doi.org/10.1111/j.14678624.1994.tb00844.x.

Wainryb, C., Shaw, L. A., Laupa, M., \& Smith, K. R. (2001). Children's, adolescents', and young adults' thinking about different types of disagreements. Developmental Psychology, 37(3), 373-386. https://doi.org/10.1037/0012-1649.37.3.373.

Williams, K. D., Govan, C. L., Croker, V., Tynan, D., Cruickshank, M., \& Lam, A. (2002). Investigations into differences between social- and cyberostracism. Group Dynamics, 6(1), 65-77. https://doi.org/10.1037/1089-2699.6.1.65. 